\title{
Robustness of the holistic seismic risk evaluation in urban centers using the USRi
}

\author{
Mabel-Cristina Marulanda · Omar D. Cardona · Alex H. Barbat
}

Received: 21 November 2007/ Accepted: 28 September 2008/Published online: 28 October 2008

(C) Springer Science+Business Media B.V. 2008

\begin{abstract}
The Urban Seismic Risk index (USRi) published in a previous article (Carreño et al., Nat Hazards 40:137-172, 2007) is a composite indicator that measures risk from an integrated perspective and guides decision-making for identifying the main interdisciplinary factors of vulnerability to be reduced or intervened. The first step of the method is the evaluation of the potential physical damage (hard approach) as a result of the convolution of the seismic hazard with the physical vulnerability of buildings and infrastructure. Subsequently, a set of social context conditions that aggravate the physical effects is also considered (soft approach). According to this procedure, the physical risk index is evaluated for each unit of analysis from existing loss scenarios, whereas the total risk index is obtained by multiplying the former index by an impact factor using an aggravating coefficient, based on variables associated with the socio-economic conditions of each unit of analysis. The USRi has been developed using the underlying holistic and multi-hazard approach of the Urban Risk Index framework proposed for the evaluation of disaster risk in different megacities worldwide. This article presents the sensitivity analysis of the index to different parameters such as input data, weights and transformation functions used for the scaling or normalization of variables. This analysis has been performed using the Monte Carlo simulation to validate the robustness of this composite indicator, understanding as robustness how the cities maintain the ranking as well as predefined risk level ranges, when compared with the deterministic results of risk. Results are shown for different cities of the world.
\end{abstract}

M.-C. Marulanda $(\bowtie) \cdot$ A. H. Barbat

Universidad Politécnica de Cataluña, Campus Norte, C/Gran Capitán sn Mod. C1,

Barcelona 08034, Spain

e-mail: mmarulan@cimne.upc.edu

A. H. Barbat

e-mail: alex.barbat@upc.edu

O. D. Cardona

Universidad Nacional de Colombia, Sede Manizales. IDEA, Cra 27 No. 64-60,

Manizales, Colombia

e-mail: odcardonaa@unal.edu.co 
Keywords Urban Seismic Risk index - Monte Carlo simulation - Sensitivity analysis · Uncertainty analysis $\cdot$ Robustness $\cdot$ Deterministic values $\cdot$ Stochastic values

\section{Introduction}

In the past, the concept of disaster risk has been defined in many cases in a fragmentary way, according to each scientific discipline involved in its appraisal. However, disaster risk requires an interdisciplinary evaluation (Cardona 2004) that takes into account not only the expected physical damage, the number and type of casualties or economic losses (direct impact), but also the conditions related to social fragility and coping capacity of the society, which favor the second-order effects (indirect impact) when a hazard event strikes an urban centre. Cardona (2001) developed a holistic approach and method for disaster risk evaluation at urban level based on a multi-criteria technique.

Using a multi-criteria approach, it was possible to evaluate the disaster risk of exposed areas using indices and indicators (Cardona 2006). This type of approach is based on a constructive rationality and it allows taking into account uncertain, incommensurable, multidimensional aspects and effects. It is a promising estimation framework for making integrated evaluations and for decision-making in multiple variable environments (Munda 2000). This process commences with the identification of imaginable variables that may "reflect" the state of a socio-technical system (as a country, region or megacity). These variables may not have

hierarchical or structu the influence of each

weight" or importance
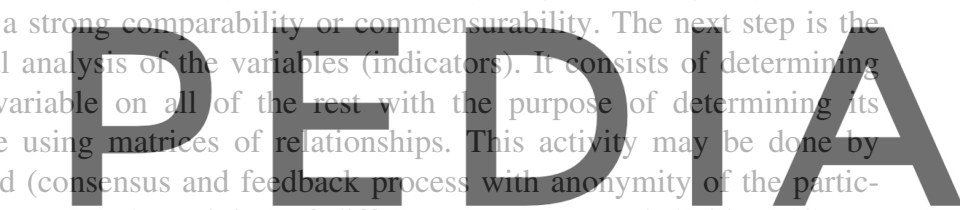

ipants) and taking into account the opinion of different experts or stakeholders (Garret

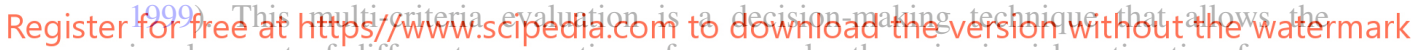
involvement of different perspectives, for example, the seismic risk estimation from a physical, economic, social, political or institutional point of view.

Carreño (2006) developed an alternative method for the Urban Risk Index based on Cardona's model (Cardona 2001; Cardona and Barbat 2000). In this method, the urban risk is evaluated using composite indicators, and the expected building damage and losses in the infrastructure obtained from simulated loss scenarios are the basic information is needed for evaluating a physical risk index in each unit of analysis. This article presents the uncertainty and sensitivity analizes of the USRi performed in order to illustrate its robustness and shows results of its application to different cities. These analyzes have been made to illustrate that for disaster risk management the deterministic approach for risk evaluation using the USRi is reliable, because the ranking of the cities and their classification by risk level ranges are similar to those obtained by Monte Carlo simulation, in which the values of the input data, the non-linear transformation functions and the weights used in the method are considered to be stochastic.

\section{The Urban Seismic Risk index, USRi}

The USRi proposed by Carreño et al. (2007) uses an integrated and comprehensive approach and describes seismic risk by means of composite indicators. The model was 
developed to guide the decision-making in risk management, helping to identify the critical zones of a city and their vulnerability from different perspectives of professional disciplines. This approach contributes to the effectiveness of risk management, inviting to the implementation or action by identifying the hard and soft weakness of the urban centre. The total urban disaster risk is measured not only in terms of the direct impact of expected physical damage but also considers indirect impact factors that account for the socio-economic fragility and coping capabilities of the city's population and its institutions. In this model, the total risk $R_{T}$ or USRi depends on the potential direct impact of earthquakes denoted as physical risk $R_{F}$, and on the indirect effects given by and impact factor $(1+F)$ based on the aggravating coefficient, $F$. Thus, it is expressed by the equation known in the field of disaster risk indicators as Moncho's Equation as follows:

$$
U S R i=R_{T}=R_{F}(1+F)
$$

where

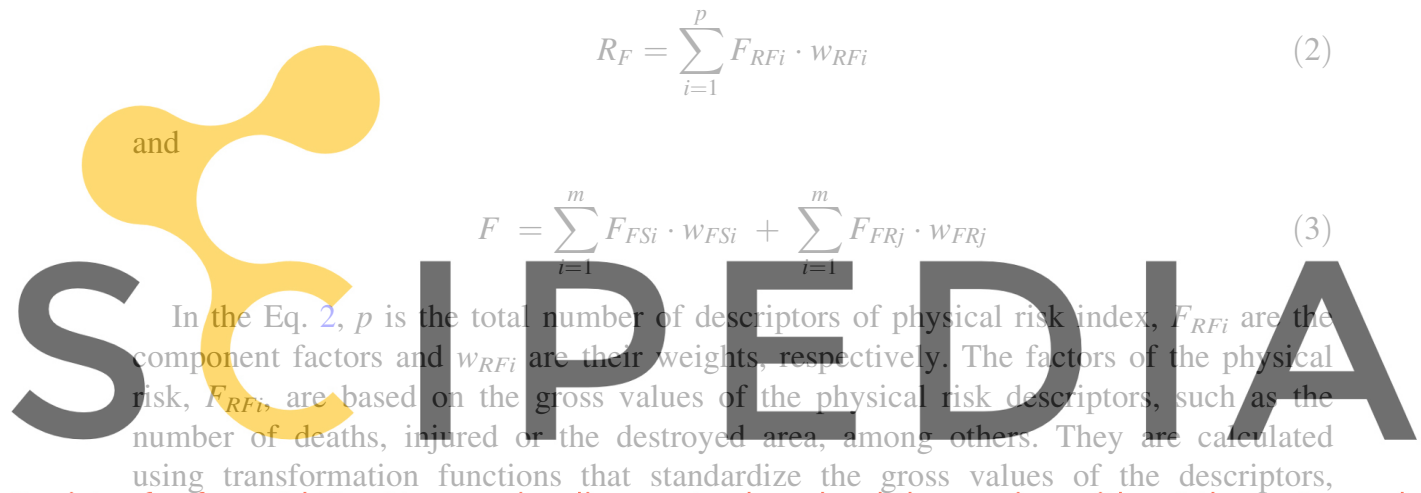

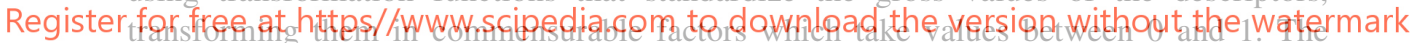

aggravating coefficient given by Eq. 3 depends on the weighted sum of a set of factors related to the socio-economic fragility, $F_{F S i}$, and the lack of resilience of the exposed context, $F_{F R j}$. In the same equation, $w_{F S i}$ and $w_{F R j}$ are the weights or influences of each $i$ and $j$ factor, and $m$ and $n$ are the total number of descriptors for social fragility and lack of resilience, respectively. These aggravating factors are also calculated using transformation functions. The weights or influences of each factor represent the relative importance of each factor and are calculated by means of the Analytic Hierarchy Process (AHP) (Saaty 1980). Figure 1 shows a schematic depiction of the Urban Risk Index (URi) for the units of analysis which could be districts, municipalities, communes or localities.

The Urban Seismic Risk index (URSi) was proposed and applied to Barcelona (Spain) and Bogota (Colombia) by Carreño et al. (2005, 2007) and to Manizales (Colombia) by Suarez (2007). Recently, the USRi has been applied to Metro Manila, The Philippines, by Earthquake Megacities Initiative (EMI 2006). In the case of Bogota, the scenarios of losses, calculated building by building, were developed by Universidad de Los Andes (2005). For the city of Barcelona probabilistic and deterministic scenarios were developed by ICC/CIMNE (2004). In Manizales the damage scenarios were obtained by ERN (2005). Details of the current approach and technique are available in Carreño et al. (2007). 


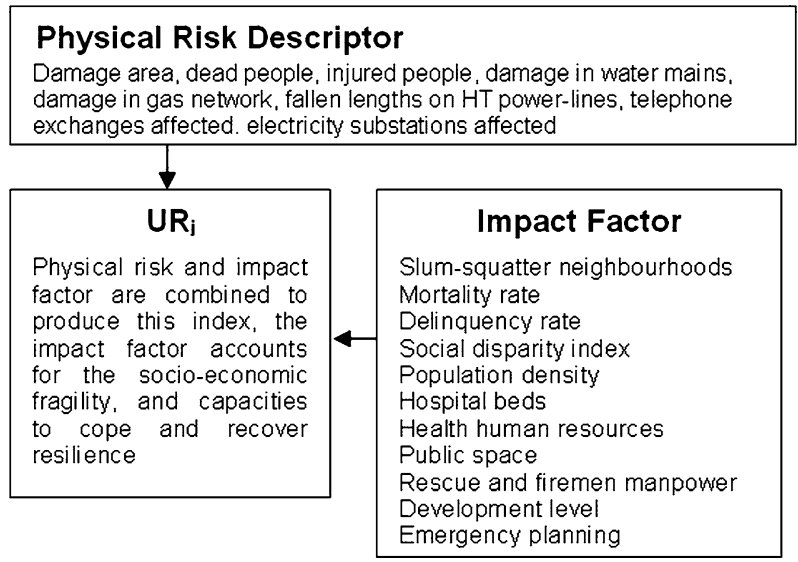

Fig. 1 Urban Risk Index (URi) formulation based on Physical Risk and Impact Factor composite indicators. Source: Megacities Indicator System (MIS) of Metro Manila, EMI (2006)

\section{Uncertainty and sensitivity analyzes}

The use of uncertainty and sensitivity analyzes may increase the objectivity and reliability of a composite indicator, and make policy inference more defensible among the stakeholders. The former structure of the composit he indicator. The latter ibutes to the output
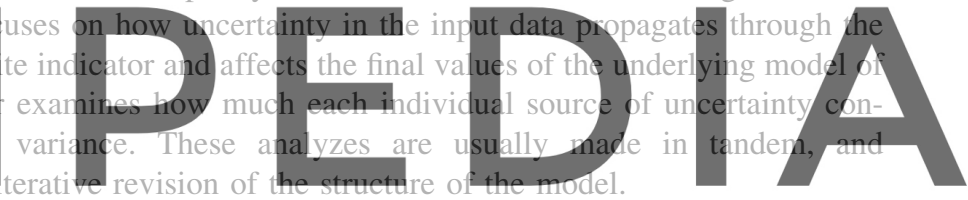

All known sources of uncertainty are properly acknowledged, and the analysis acts to

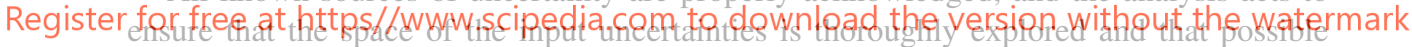

interactions are captured by the analysis. Some of the uncertainties might be the result of a parametric estimation, but others may be linked to alternative formulations of the problem, or different framing assumptions which might reflect different views of reality, as well as different value judgments posed on it.

Sensitivity analysis complements uncertainty analysis because it studies how the variation of the values of a composite indicator can be apportioned quantitatively to different sources of variation (e.g., weights and transformation functions) (JRC-EC 2002). A sensitivity analysis is the process of varying the parameters of the inputs to a model over a reasonable range and observing the relative change in model response. The input is what is allowed to vary in order to study its effect on the output. In turn, a sensitivity analysis will then provide information to the modelers on the relative importance of the values of these parameter values in determining the output. These are used to assess how robust the results are to uncertain decisions or assumptions about the data and the methods that are used; it also helps to build confidence in the model by studying the uncertainties that are often associated with the parameters in models. Many parameters describing dynamic models are quantities that are very difficult or even impossible to measure accurately in the real world. Sensitivity analysis allows determining what level of accuracy is necessary for a parameter to make the model sufficiently useful and valid (JRC-EC 2003).

Models cannot be validated, in the sense of "be proven true". Indeed, it is only possible to make an extensive corroboration, meaning by this, that the model has survived a series 
of tests of internal consistency or relative to its capacity to explain or predict "world" in a convincing and parsimonious way. Like scientific theories, models may be given pedigrees which help us to judge upon their quality. Pedigrees look at past usage of the model, status of the proponents, degree of acceptance by peers and so on. Within pedigrees, model quality is more associated to "fitness for purpose", that is, to a specific purpose than to the model's intrinsic fabric (Saltelli 2006; Gall 2007).

One of the methods for analyzing uncertainty propagation is the Monte Carlo simulation, where the goal is to determine how random variation affects the sensitivity, performance or reliability of the model. This is a technique that uses sets of random numbers as input parameters and probability distributions for iteratively evaluating a deterministic model, that is, the responses of a system depend on a set of random variables, whose marginal probabilistic description is known. By means of well-tested algorithms, a large population of samples of each of these variables can be generated, in such a way that the closer the histograms of density and cumulative distributions, the larger the population. An equally large population of output responses can be obtained by making use of the deterministic code of analysis of the system each time with a different set of random deviates of the input variables (Hurtado and Barbat 1998).

This method is often used when the model is complex, non-linear or involves more than a couple of uncertain parameters. Depending on the sample size of the simulation chosen, the variation will be different, that is, the larger the sample size, the smaller the difference will be. The accuracy of the result depends upon the number of simulated observations, how realistic the model is and how well the input distributions represent the true uncertainty of

variation.
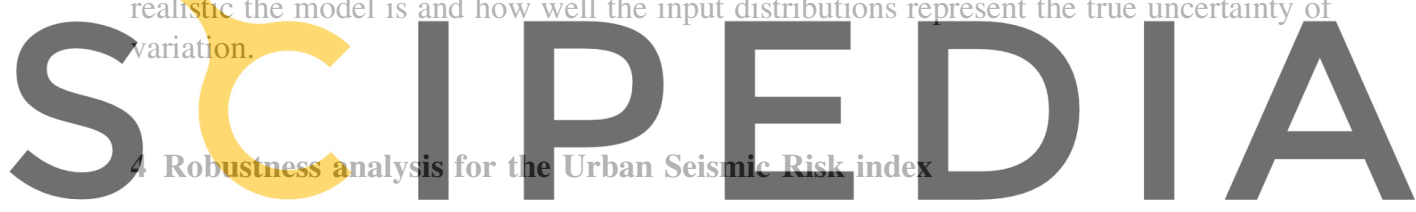

In the case of the holistic evaluation of seismic risk, sensitivity and uncertainty analyzes of Register for tree at https/ www.scipedia,com to download the version without the watermark ation in the values of the USRi (or total risk, $R_{T}$ ) can be apportioned, qualitatively or quantitatively, to different sources of variation, and how this given index or composite indicator depends upon the information fed into it. In other words, once the proposed model (composite indicator) is determined, it is important to analyse how much the results are influenced by uncertainty in the source data or uncertainty in the model itself (e.g., weights and transformation functions), because of the stakeholders' subjectivity or plurality of perspectives. For this purpose, a Monte Carlo-based simulation was performed.

The random inputs, for each set previously mentioned, were obtained individually by using uniform distributions in each interval. It would be possible to consider other distribution function allowing to identify some particular features of the problem but, in this case, in which the main objective of the article is to provide results relevant for decisionmaking according to ranges of risk, a uniform distribution proves to be sufficient. In the same way, random values for simultaneous variation of all the sets were obtained. The minimum and maximum values were chosen according to experts' opinions to indicate the interval or reasonable range of uncertainty for each input parameters; i.e., according to possible values in reality and relevant for decision-making in disaster risk management. Intervals of uncertainty of the transformation functions of descriptors and weights of the factors were determined by choosing the maximum and minimum values within a percentage of variation of $20 \%$ above and $20 \%$ below of original data, due to the original 
limits of each transformation function being deterministic using existing information about previous disasters and experts opinions.

By this way, thousands of stochastic results were created with random inputs of each parameter (input data, transformation functions, weights and all simultaneously) for each territorial urban unit of analysis (see Table 1). Clearly, the more variables we promote to the rank of input, allowing them to vary, the more the model prediction can be expected to vary. This could lead to a situation where having incorporated all uncertainties, the model prediction varies so wildly as to be of no practical use. In order to provide a concise summary of the results, the mean, median, standard deviation, maximum and minimum values and a few other summarized statistics to describe the resulting distribution are given (see Table 2). Likewise, a histogram was created for visualizing the uncertainty of results, which illustrates the profile of results, the uncertainty degree and the existing distribution. In addition, the cumulative distribution function was included in each graph to illustrate the percentage of data points that are below a value or point of interest.

Figure 2 shows an example of a histogram, and Table 1 illustrates an example of a statistic summary of the Monte Carlo simulation.

Once the results were calculated through Monte Carlo simulation, the variability or volatility graphics were built to compare the stochastic results of the USRi with the deterministic results obtained from the methodology. Figures 3 and 4 illustrate minimum $(\triangleright)$, maximum $(\times)$ and mean $(\square)$ values and the bars correspond to the deterministic results obtained for each territorial unit. It can be seen that for the variability of each parameter, the variability of results is not significant to change the ranking of the

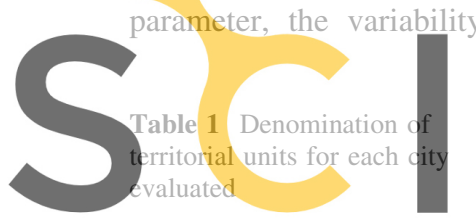

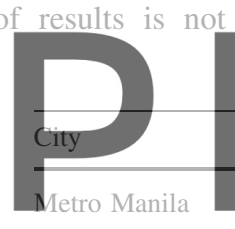

Barcelona

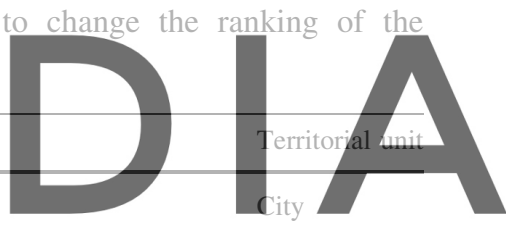

District

Register for free at https//www.scipediagem to download the version withoutotherumatermark

Table 2 Example of statistic summary of the results for Mandaluyong City in Metro Manila with stochastic weights

Statistics summary

Sample size (N): 5000

Central tendency (Location)

Mean: 0.4

Median: 0.4

StErr: 0.00

Spread

StDev: 0.04

Max: 0.49

Min: 0.32

Range: 0.17

Shape

Skewness: 0.0435

Kurtosis: -1.0225

Quantiles, percentiles, intervals

$90 \%$ Interval

$\mathrm{Q}(0.05): 0.343$

$\mathrm{Q}(0.95): 0.459$

Alpha (a): 0.05

$\%$ Interval: $95 \%$

Probabilities

$\operatorname{Pr}(y<0.33)=0.44 \%$

$\operatorname{Pr}(y>0.4)=49.93 \%$

$\operatorname{Pr}(0.33<y<0.4)=49.63 \%$

Alpha (a): 0.5037 


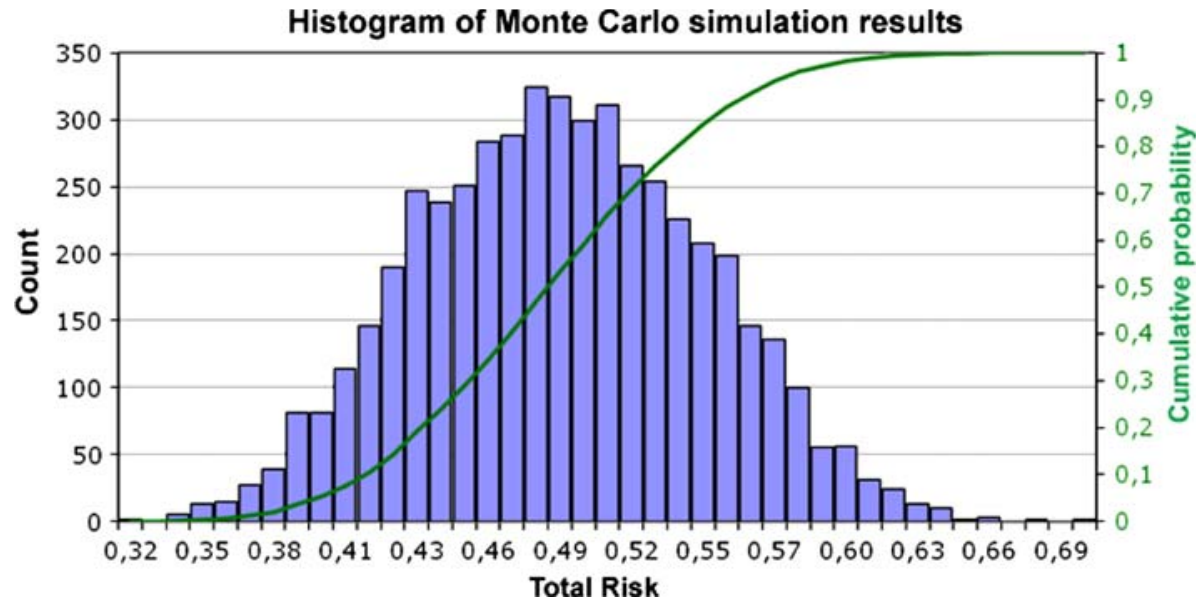

Fig. 2 Example of a histogram of the results of USRi for Pateros City in Metro Manila with stochastic weights
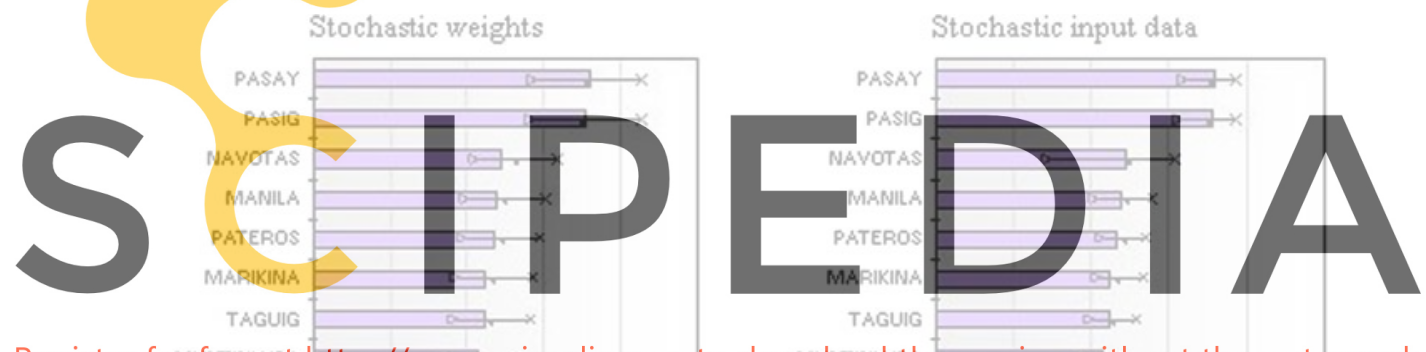

Register forluree at https//wWw:seipedia.com to
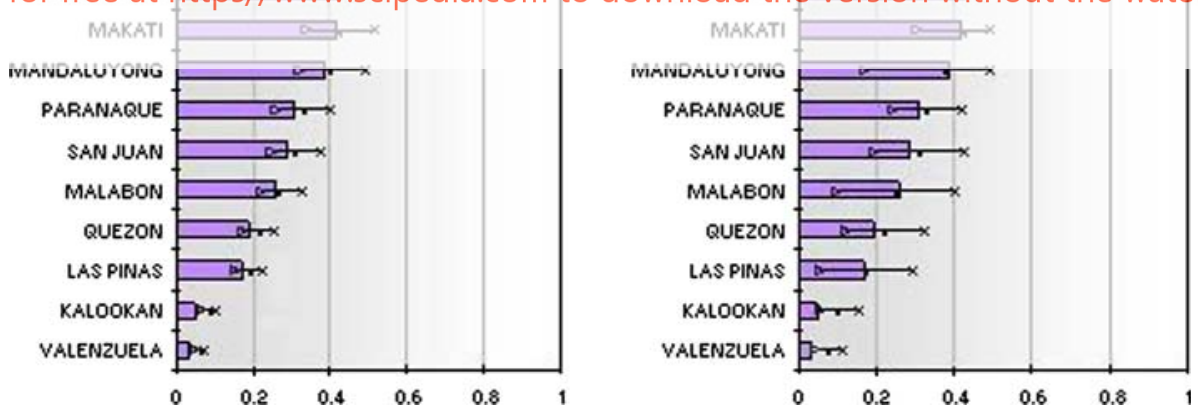

Fig. 3 Variation of the simulation results for stochastic weights and stochastic data. Bars represent the deterministic or crisp values

territorial units. The uncertainty is bigger in the case of the simultaneous variation of all parameters. Figure 5 shows the results of different cities in order to illustrate that in extreme or marginal cases it is possible that the ranking and the risk level range change but, in the same way, and that in the most cases they do not change. For example, the probability that the USRi of Kalookan be less than 0.15, i.e., to belong to the low range, is of $93 \%$ or, for Makati, to be greater than 0.30 is of $99 \%$, i.e., $77 \%$ to be in medium-high 

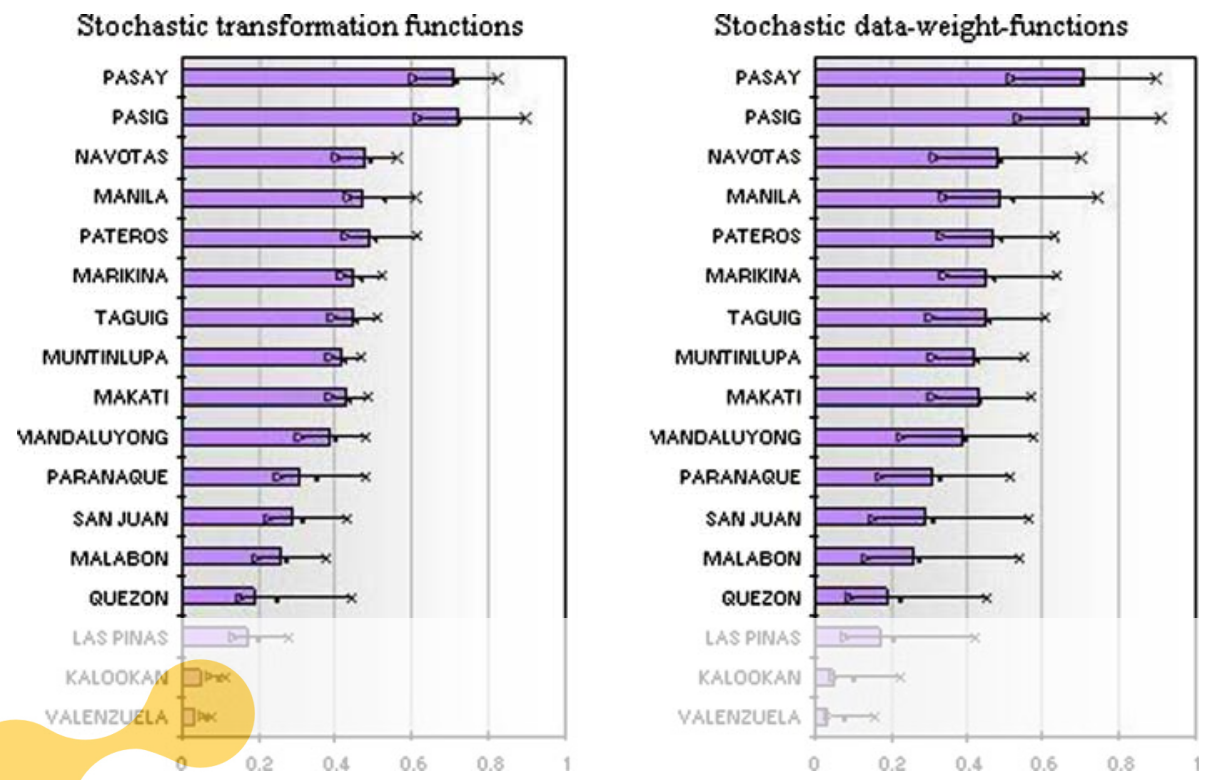

Fig. 4 Variation of the simulation results for stochastic transformation functions and for stochastic data, weights and transformation functions. Bars represent the deterministic or crisp values
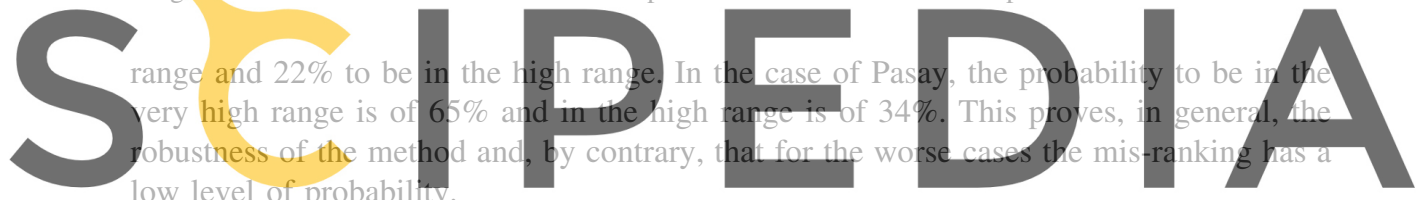

Table 3 shows that the results obtained through simulation are similar to the results Register for free at. https / www scipedia.com to download the version without the watermark

functions of the USRi method applied to Metro Manila. The overall results show that, the territorial units of this megacity vary slightly in their rankings. Some units fluctuate at one position. In other urban centres, such as Barcelona (Table 4) and Manizales (Table 5), where the method has been applied and where a similar sensitivity analysis has been made, the results are similar. Only in the case of Bogota (Table 6) some localities have been more volatile, showing changes of three positions; however, this fact is not relevant for decision-making measures, because these measures are defined according to the risk levels shown in Table 7 and the territorial units does not change of level drastically.

In Metro Manila, according to the classification of the total risk by levels, all cities maintain the same level excepting San Juan which changes the range from medium-high to medium-low because the total risk result for crisp values is equal to 0.29 and for stochastic values the result is above 0.30 .

In the case of Barcelona, according to the classification of the total risk by levels, all the districts maintain the same level excepting San Marti district which shows changes of range from low to medium-low because the total risk result for deterministic values is equal to 0.13 and for stochastic values the result is above 0.16 ; for the simultaneous variation of all the parameters, the result is over 0.15 . Likewise, the Example district shows a change of range from low to medium-low in the case of stochastic transformation 


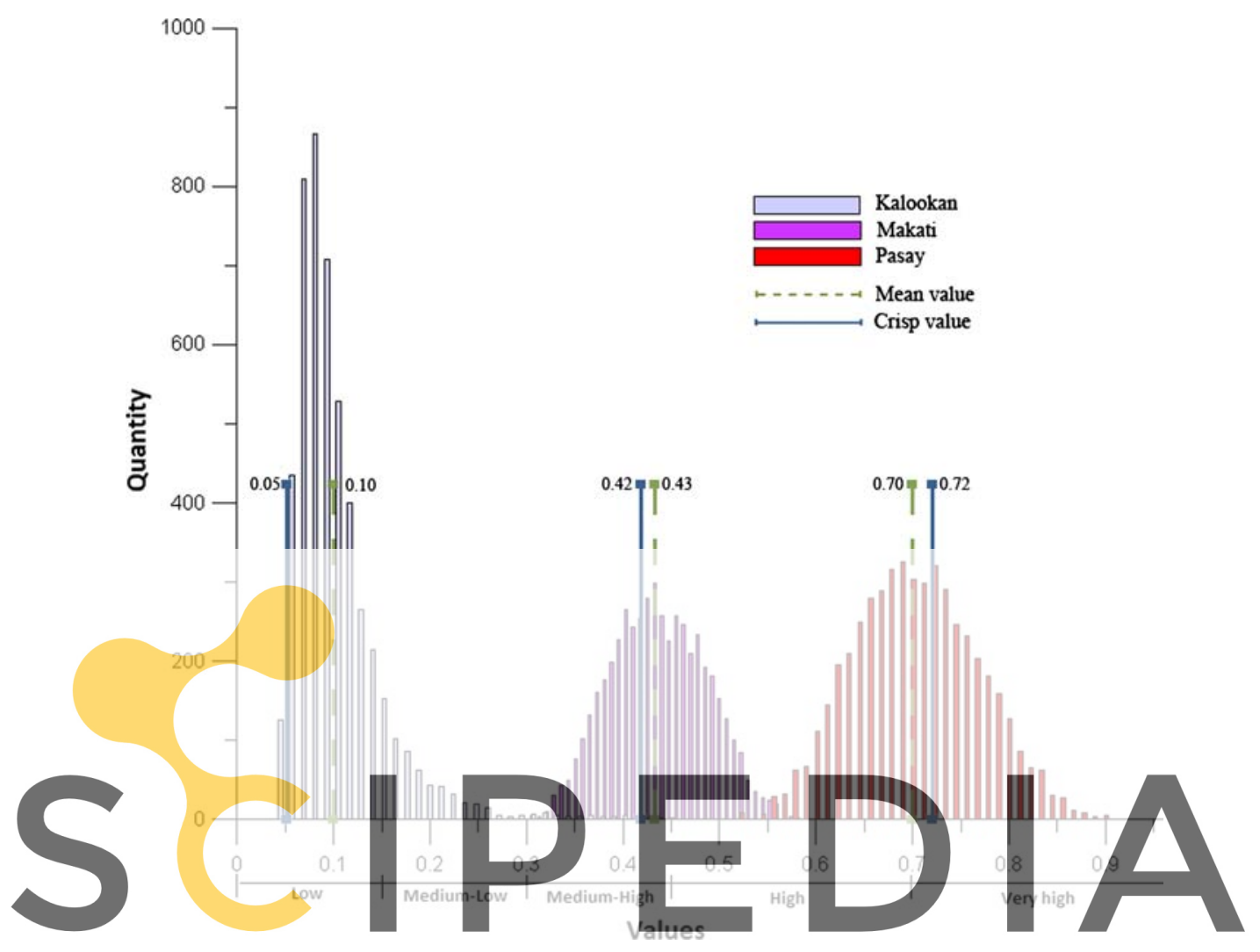

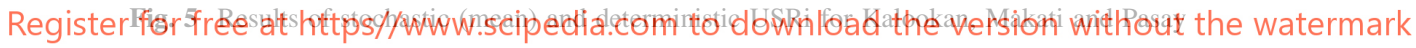

functions because the total risk result for crisp values is the same and for stochastic values the result is above 0.15 .

The communes of the city of Manizales, Colombia, maintain the same level with exception of La Fuente and Palogrande, for the variation of all parameters, cases in which there was a change of range from low to medium-low, and from medium-low to mediumhigh, respectively.

In the case of the city of Bogota, Colombia, according to the classification of the total risk by levels, the localities maintain a very similar position in all parameters variation. Some localities such as Engativa and Puente Aranda present changes of their rank in the case of stochastic weights and functions, because the values of the total risk are very similar and thus this result can be produced by a slight variation of the values. Other rank changes can be observed for the same reason. In addition, it is possible to observe the change of the risk level for Santa Fe from very high to high, because the total risk result for deterministic values is equal to 0.70 and for stochastic values the result was 0.68. Nevertheless, this fact is not relevant because the change of the value for this locality is in the limit of the two levels, so that very small variation can produce the change; what is important is to interpret that this locality is located in the upper limit of a high-risk level. 
Table 3 Comparison between stochastic results and deterministic resulf of USRi, positions and classification of Metro Manila cities by risk levels

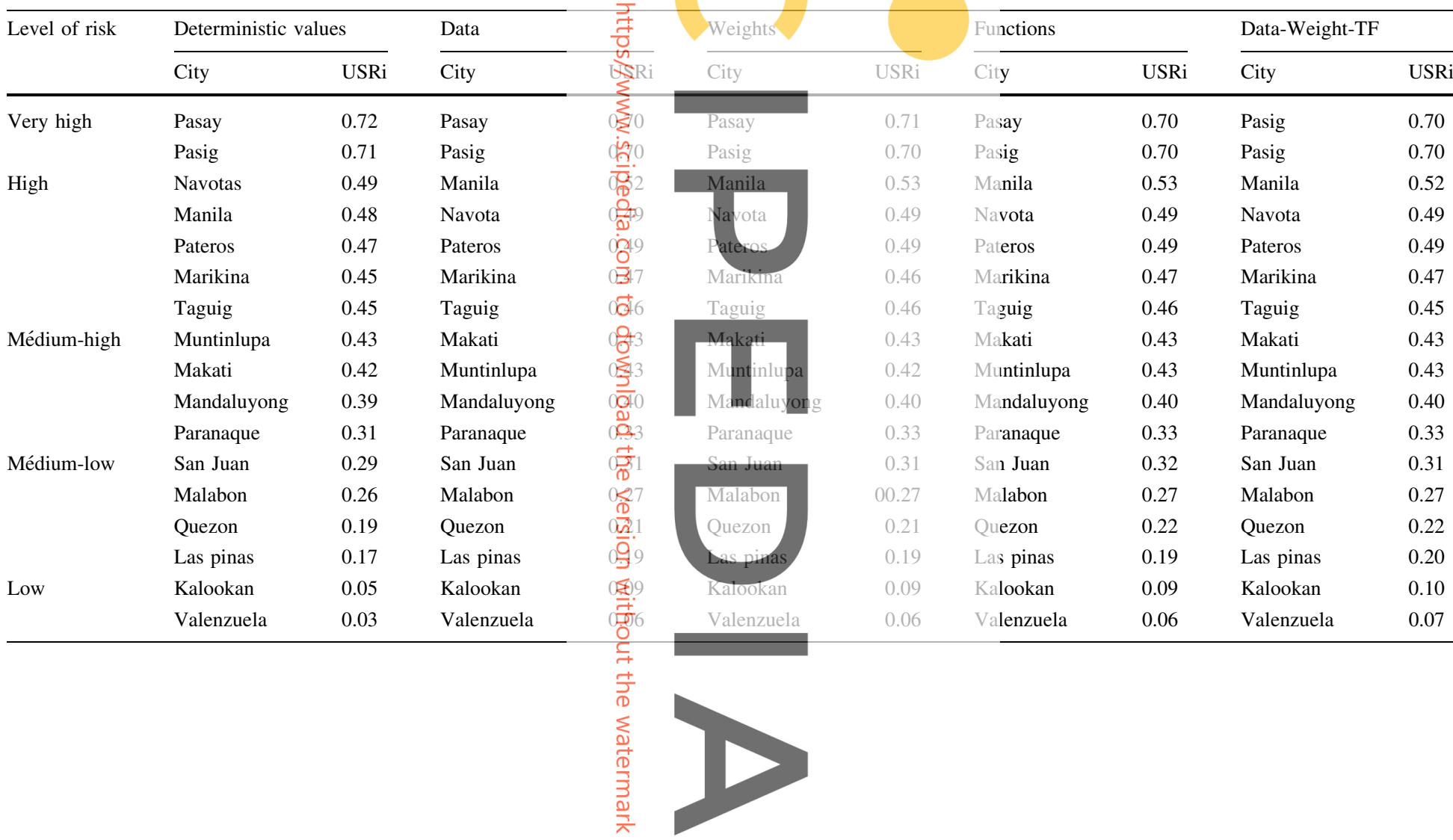


Table 4 Comparison between stochastic results and crisp results of USRi, positions and classification of Barcelona's districts by risk levels

\begin{tabular}{|c|c|c|c|c|c|c|c|c|c|c|}
\hline Level of risk & \multicolumn{2}{|l|}{ Deterministic values } & \multicolumn{2}{|l|}{ Data } & \multicolumn{2}{|l|}{ Weights } & \multicolumn{2}{|l|}{ Functions } & \multicolumn{2}{|l|}{ Data-Weight-TF } \\
\hline Medium-high & Ciutat Vella & 0.39 & Ciutat Vella & 0.39 & Ciutat Vella & 0.37 & Ciutat Vella & 0.42 & Ciutat Vella & 0.37 \\
\hline \multirow{3}{*}{ Medium-low } & Eixample & 0.12 & Eixample & 0.12 & Eixample & 0.12 & Eixample & 0.15 & Eixample & 0.13 \\
\hline & Sant Montjuic & 0.06 & Sant Andreu & 0.07 & Sant Andreu & 0.07 & Sant Andreu & 0.08 & Nou Barris & 0.07 \\
\hline & Sant Andreu & 0.06 & Nou Barris & 0.07 & Nou Barris & 0.07 & Sant Montjuic & 0.08 & Sant Andreu & 0.07 \\
\hline \multirow[t]{4}{*}{ Low } & Gracia & 0.05 & Gracia & 0.06 & Gracia & 0.06 & Gracia & 0.07 & Gracia & 0.06 \\
\hline & Les Corts & 0.05 & Horta Guinardo & 0.06 & Horta Guinardo & 0.06 & Horta Guinardo & 0.06 & Les Corts & 0.05 \\
\hline & Horta Guinardo & 0.04 & Les Corts & 0.06 & Les Corts & 0.06 & Les Corts & 0.06 & Horta Guinardo & 0.05 \\
\hline & Sarriá Sant Gervasi & 0.04 & Sarriá Sant Gervasi & 0.05 & Sarriá Sant Gervasi & 0.05 & Sarriá Sant Gervasi & 0.06 & Sarriá Sant Gervasi & 0.05 \\
\hline
\end{tabular}


Table 5 Comparison between stochastic results and crisp results of USRi, positions and classification of Manizales' localities by risk levels

\begin{tabular}{|c|c|c|c|c|c|c|c|c|c|c|}
\hline \multirow[t]{2}{*}{ Level of risk } & \multicolumn{2}{|c|}{ Deterministic values } & \multicolumn{2}{|l|}{ Data } & \multicolumn{2}{|l|}{ Weights } & \multicolumn{2}{|l|}{ Functions } & \multicolumn{2}{|l|}{ Data-Weight-TF } \\
\hline & Locality & USRi & Locality & USRi & Locality & USRi & Locality & USRi & Locality & USRi \\
\hline \multirow[t]{2}{*}{ Very high } & San Jose & 0.97 & San Jose & 0.96 & San Jose & 0.96 & San Jose & 0.96 & San Jose & 0.99 \\
\hline & Cumanday & 0.75 & Cumanday & 0.76 & Cumanday & 0.76 & Cumanday & 0.76 & Cumanday & 0.87 \\
\hline High & La Macarena & 0.55 & La Macarena & 0.57 & La Macarena & 0.57 & La Macarena & 0.57 & La Macarena & 0.60 \\
\hline \multirow[t]{2}{*}{ Medium-high } & Atardeceres & 0.33 & Atardeceres & 0.34 & Atardeceres & 0.34 & Atardeceres & 0.35 & Atardeceres & 0.41 \\
\hline & Universitaria & 0.30 & Universitaria & 0.32 & Universitaria & 0.32 & Universitaria & 0.32 & Universitaria & 0.33 \\
\hline \multirow[t]{2}{*}{ Medium-low } & Palogrande & 0.24 & Palogrande & 0.25 & Palogrande & 0.24 & Palogrande & 0.25 & Palogrande & 0.29 \\
\hline & La Estación & 0.21 & La Estación & 0.22 & La Estación & 0.21 & La Estación & 0.22 & La Estación & 0.28 \\
\hline \multirow[t]{4}{*}{ Low } & La Fuente & 0.11 & La Fuente & 0.14 & La Fuente & 0.14 & La Fuente & 0.14 & La Fuente & 0.16 \\
\hline & Ciud Norte & 0.07 & Ciud Norte & 0.10 & Ciud Norte & 0.10 & Ciud Norte & 0.10 & Ciud Norte & 0.10 \\
\hline & Ecot Cerro Oro & 0.04 & Ecot Cerro Oro & 0.08 & Ecot Cerro Oro & 0.07 & Ecot Cerro Oro & 0.07 & Ecot Cerro Oro & 0.09 \\
\hline & Tesorito & 0.00 & Tesorito & 0.04 & Tesorito & 0.03 & Tesorito & 0.03 & Tesorito & 0.04 \\
\hline
\end{tabular}


Table 6 Comparison between stochastic results and crisp results of USRi, positions and classification of Bogota's localities by risk levels

\begin{tabular}{|c|c|c|c|c|c|c|c|c|c|c|}
\hline \multirow[t]{2}{*}{ Level of risk } & \multicolumn{2}{|c|}{ Deterministic values } & \multicolumn{2}{|l|}{ Data } & \multicolumn{2}{|l|}{ Weights } & \multicolumn{2}{|l|}{ Functions } & \multicolumn{2}{|l|}{ Data-Weight-TF } \\
\hline & Locality & USRi & Locality & USRi & Locality & USRi & Locality & USRi & Locality & USRi \\
\hline \multirow[t]{7}{*}{ Very high } & Fontibón & 1.08 & Fontibón & 1.05 & Fontibón & 1,05 & Fontibón & 1.05 & Fontibon & 1.04 \\
\hline & Puente Aranda & 0.89 & Puente Aranda & 0.88 & Engativá & 0.88 & Engativá & 0.88 & Puente Aranda & 0.88 \\
\hline & Engativá & 0.88 & Engativá & 0.88 & Puente Aranda & 0.88 & Puente Aranda & 0.88 & Engativa & 0.87 \\
\hline & Suba & 0.77 & Suba & 0.76 & Suba & 0.76 & Suba & 0.77 & Suba & 0.76 \\
\hline & Los Mártires & 0.72 & Los Mártires & 0.72 & Los Mártires & 0.72 & Kennedy & 0.72 & Los Martires & 0.72 \\
\hline & Kennedy & 0.72 & Kennedy & 0.71 & Kennedy & 0.71 & Los Mártires & 0.72 & Kennedy & 0.71 \\
\hline & Santa Fe & 0.70 & San Cristobal & 0.69 & San Cristobal & 0.69 & San Cristobal & 0.70 & San Cristobal & 0.70 \\
\hline \multirow[t]{10}{*}{ High } & San Cristóbal & 0.68 & Santa $\mathrm{Fe}$ & 0.68 & Santa Fe & 0.68 & Santa Fe & 0.68 & Santa Fe & 0.68 \\
\hline & Ciudad Bolivar & 0.62 & Ciudad Bolivar & 0.63 & Ciudad Bolivar & 0.62 & Ciudad Bolivar & 0.63 & Usme & 0.63 \\
\hline & Usme & 0.62 & Usme & 0.63 & Usme & 0.62 & Usme & 0.63 & Ciudad Bolivar & 0.63 \\
\hline & Usaquen & 0.61 & Rafael Uribe & 0.62 & Rafael Uribe & 0.61 & Rafael Uribe & 0.61 & Rafael Uribe & 0.62 \\
\hline & Rafael Uribe & 0.60 & Usaquen & 0.60 & Usaquen & 0.60 & Usaquen & 0.60 & Usaquen & 0.60 \\
\hline & La Candelaria & 0.53 & Tunjuelito & 0.53 & Tunjuelito & 0.53 & La Candelaria & 0.53 & La Candelaria & 0.53 \\
\hline & Tunjuelito & 0.52 & La Candelaria & 0.53 & La Candelaria & 0.52 & Antonio Nariño & 0.49 & Tunjuelito & 0.53 \\
\hline & Antonio Nariño & 0.50 & Antonio Nariño & 0.49 & Antonio Nariño & 0.49 & Tunjuelito & 0.47 & Antonio Nariño & 0.49 \\
\hline & Chapinero & 0.45 & Chapinero & 0.46 & Chapinero & 0.45 & Teusaquillo & 0.46 & Chapinero & 0.46 \\
\hline & Teusaquillo & 0.45 & Teusaquillo & 0.45 & Teusaquillo & 0.45 & Chapinero & 0.45 & Teusaquillo & 0.45 \\
\hline \multirow[t]{2}{*}{ Medium-high } & Barrios Unidos & 0.34 & Bosa & 0.34 & Bosa & 0.34 & Bosa & 0.35 & Barrios Unidos & 0.35 \\
\hline & Bosa & 0.32 & Barrios Unidos & 0.34 & Barrios Unidos & 0.33 & Barrios Unidos & 0.34 & Bosa & 0.35 \\
\hline
\end{tabular}


Table 7 Risk levels ranges for USRi

\begin{tabular}{lllll}
\hline Very high & High & Medium-high & Medium-low & Low \\
\hline $0.70-1.20$ & $0.45-0.69$ & $0.30-0.44$ & $0.15-0.29$ & $0.00-0.14$ \\
\hline
\end{tabular}

Classification of risk by ranges has a special interest because, for risk management implications, it is more relevant to take into account the level of risk of territorial units of a megacity than its final numerical value.

\section{Conclusions}

Robustness is a basic attribute of the quality of a risk evaluation method, and the purpose of this article has been to prove the robustness of the USRi method.

Public policy, despite what many believe, is well linked to the evaluation technique that is used to guide that policy. The quality, or fitness for purpose, of an evaluation technique, called by some "its scientific pedigree," has an unsuspecting influence on the development of a policy. If the evaluation, for instance, invites to the policy implementation, it is much more effective than if its results are restricted to identifying the mere existence of weaknesses. The holistic evaluation of seismic risk using the USRi facilitates the integrated risk management by the different stakeholders involved in riskreduction decision-making. Once the results have been obtained for each locality or district, it is easy to identify the most relevant aspects of the total risk index. The results can be verified and the mitigation priorities can be established as regards the prevention and planning actions to modify those conditions (sub-indicators) having a greater influence on risk. This technique allows comparing risks among different cities or megacities, therefore the USRi allows using a common "rule" of measurement to compare and benchmark the results.

According to the comparison of the results of sensitivity analysis based on Monte Carlo simulations and the results obtained by the holistic seismic risk evaluation here described, it is possible to conclude that the USRi method is robust. It is not excessively sensitive to slight variations in the input data and to small changes in the modeling parameters, such as weights and transformation functions. The results do not show important or extreme changes. If the range of variation of data and parameters is reasonable, as it is in the case of seismic risk, the results of the model will be stable and reliable. Classification by ranges of risk has special interest, because it is more relevant to take into account the level of risk where a territorial unit is located than its final numerical value for risk management implications.

The quality of the evaluation technique is understood as its ability to assure a certain set of requirements or desirable attributes. These attributes are its applicability, transparency, presentation, legitimacy and robustness. Thus, its scientific pedigree will depend on the fulfillment or compliance with these properties. Applicability is linked to the fitness of the model to the problem, to its goals and completeness, and to the accessibility, aptitude and trustworthiness of the required information. Transparency is related to the structuring of the problem, its ease of use, flexibility and adaptability, and the intelligibility of the model or algorithm. Presentation is related to the transformation of information, the visualization and comprehensibility of the results. Legitimacy is linked 
or associated with the role of the analyst, the control and contrasting, the possibility of verification, and the acceptance and consensus of decision evaluators and makers. Finally, the robustness is related to the stability and reliability of the method to deal with the uncertainty of input data and the modeling parameters. The design of the USRi, based on the holistic approach for seismic risk evaluation, covers all the attributes of quality that have been previously mentioned.

Acknowledgments The authors express gratitude to the Inter-American Development Bank (IDB) for the financial support through the Information and Indicators Program for Disaster Risk Management for Latin America and the Caribbean (ATN/JF-7907-RG Operation), to the ProVention Consortium Earthquake and Megacities Initiative (EMI) for the application of the USRi to Metro Manila and Istanbul, and to the Ministry of Education and Science of Spain, PROFIT program: project "Development of new technologies in materials and processes of construction of components oriented to its integration in buildings" (HABITAT 2030) (PSS-380000-2006-10).

\section{References}

Cardona OD (2001) Estimación Holística del Riesgo Sísmico utilizando Sistemas Dinámicos Complejos. $\mathrm{PhD}$ Thesis, Technical University of Catalonia, Barcelona, Spain

Cardona OD (2004) The need for rethinking the concepts of vulnerability and risk from a holistic perspective: a necessary review and criticism for effective risk management. In: Bankoff G, Frerks G, Hilhorst D (eds) Mapping vulnerability: disasters, development and people. Earthscan Publishers, London, pp 37-51

Cardona OD (2006) A system of indicators for disaster risk management in the Americas. In: Birkmann J (ed) Measuring vulnerability to hazards of natural origin: towards disaster resilient societies. UNU Press, Tokyo, pp 189-209

Cardona OD, Barbat AH (2000) El Riesgo Sísmico y su Prevención. Calidad Siderúrgica, Madrid

Carreño ML (2006) Técnicas innovadoras para la evaluación del riesgo sísmico y su gestión en centros urbanos: Acciones ex ante y ex post. PhD Thesis, Technical University of Catalonia, Barcelona, Spain

Carreño ML, Cardona OD, Barbat AH (2005) Seismic risk evaluation for an urban centre. International Conference 250th anniversary of the 1755 Lisbon earthquake, Lisbon

Carreño ML, Cardona OD, Barbat AH (2007) Urban seismic risk evaluation: a holistic approach. Nat Hazards 40:137-172. doi:10.1007/s11069-006-0008-8

de los Andes U (2005) Seismic risk and loss scenarios of Bogotá (in Spanish), Centro de Estudios sobre Desastres y Riesgos CEDERI. Dirección de Prevención y Atención de Emergencias, DPAE, Bogotá

EMI (2006) Megacity Indicators System MIS: Implementation in Metro Manila, 3 cd program of Earthquake and Megacities Inititative EMI, Pacific Disaster Center, ProVention Consortium

ERN (2005) Seismic information system of Manizales-Risk (in Spanish), SISMAN + Riesgo, Evaluación de Riesgos Naturales ERN. National Planning Department, World Bank, Bogota

Gall M (2007) Indices of social vulnerability to natural hazards: a comparative evaluation. Doctoral Thesis, Department of Geography of the University of South Carolina

Garret MJ (1999) Health futures. World Health Organization, Geneva

Hurtado JE, Barbat AH (1998) Monte Carlo techniques in computational stochastic mechanics. Archives of Computational Methods in Engineering 5(1):3-30

ICC/CIMNE (2004) An advanced approach to earthquake risk scenarios with applications to different European towns, WP08 Application to Barcelona, RISK-UE Project

JRC-EC (2002) State-of-the-art report on current methodologies and practices for composite indicator development. Applied Statistics Group, Joint Research Centre, European Commission, Institute for Protection and Security of the Citizen Technological and Economic Risk Management, Ispra, Italy

JRC-EC (2003) First workshop on composite indicators of country performance. Applied Statistics Group, Joint Research Centre, European Commission, Institute for Protection and Security of the Citizen Technological and Economic Risk Management, Ispra, Italy

Munda G (2000) Multicriteria methods and process for integrated environmental assessment. In: Oñate E, Garcia-Sicilia F, Ramallo L (eds) Métodos Numéricos en Ciencias Sociales (MENCIS 2000). CIMNEUPC, Barcelona

Saaty TL (1980) The analytic hierarchy process. McGraw-Hill Book Co, NY 
Saltelli A (2006) The critique of modeling and sensitivity analysis in the scientific discourse. An overview of good practices. Institute for the Protection and Security of the Citizen, European Commission, Luxemburg, ISSN: 1018-5593, ISBN: 92-79-03130

Suarez DC (2007) Development of disaster risk and risk management indicators at urban level for diagnostic and planning in Manizales (in Spanish). M.Sc Thesis, National University of Colombia, Manizales 